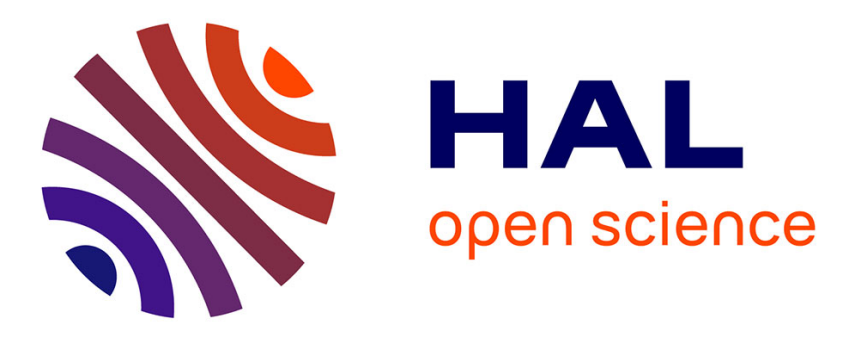

\title{
Photoinduced reversible spin-state switching of an Fe III complex assisted by a halogen-bonded supramolecular network
}

Ie-Rang Jeon, Corine Mathonière, Rodolphe Clerac, Mathieu Rouzières, Olivier Jeannin, Elzbieta Trzop, Eric Collet, Marc Fourmigué

\section{To cite this version:}

Ie-Rang Jeon, Corine Mathonière, Rodolphe Clerac, Mathieu Rouzières, Olivier Jeannin, et al.. Photoinduced reversible spin-state switching of an Fe III complex assisted by a halogenbonded supramolecular network. Chemical Communications, 2017, 53 (74), pp.10283-10286. 10.1039/C7CC03797J . hal-01596582

\section{HAL Id: hal-01596582 \\ https://hal.science/hal-01596582}

Submitted on 9 Mar 2018

HAL is a multi-disciplinary open access archive for the deposit and dissemination of scientific research documents, whether they are published or not. The documents may come from teaching and research institutions in France or abroad, or from public or private research centers.
L'archive ouverte pluridisciplinaire HAL, est destinée au dépôt et à la diffusion de documents scientifiques de niveau recherche, publiés ou non, émanant des établissements d'enseignement et de recherche français ou étrangers, des laboratoires publics ou privés. 


\title{
Photoinduced reversible spin-state switching of an Fe"' complex assisted by a halogen-bonded supramolecular networkt
}

\author{
le-Rang Jeon, ${ }^{* a}$ Corine Mathonière, ${ }^{b c}$ Rodolphe Clérac, ${ }^{\text {de }}$ Mathieu Rouzières, ${ }^{\text {de }}$ Olivier Jeannin, ${ }^{a}$ \\ Elzbieta Trzop, ${ }^{f}$ Eric Collet, ${ }^{f}$ and Marc Fourmigué*a
}

The organization of a molecular Fe"' complex embedded in a halogen-bonded 2D network is chemically tuned to trigger temperature and light-induced spin-state switching. We attribute the associated magnetic properties and the unprecedented photoswitching effect to the optimized structural confinement provided by the presence of the supramolecular host framework.

Photoswitching between electronic states of molecules in solid state is a continuous challenge for both technological applications and fundamental science research. ${ }^{1}$ Spin crossover complexes, that undergo an equilibrium between a high-spin and a low-spin electronic configurations, can offer such an optically switchable bistability, known as light-induced excited spin state trapping or the so-called LIESST effect. ${ }^{2}$ Since its discovery over 30 years ago, the reported examples exhibiting this effect have been predominantly $\mathrm{Fe}^{\text {II }}$ complexes. ${ }^{3}$ In contrast, the manifestation of the LIESST effect in $\mathrm{Fe}^{\text {III }}$ complexes remains scarce. ${ }^{4-8}$ This has been attributed to a smaller elongation of the Fe-ligand distance, relative to that of Fe", which lead to a short lifetime of the photoinduced metastable state. ${ }^{4,5,9}$

To prevent this fast relaxation from a metastable state to the ground state, a severe distortion of the metal coordination environment, in conjunction with the introduction of extensive intermolecular $\pi-\pi$ interactions, has been proposed. ${ }^{5}$ Albeit several successful examples, this strategy is not a guarantee for most Fe" complexes. ${ }^{10}$ Recently, a Fe ${ }^{\text {III }}$ complex inserted into a metal-oxalate network has been reported to show the LIESST effect, suggesting that a structural confinement of the $\mathrm{Fe}^{\text {III }}$ complex may be an

a. Institut des Sciences Chimiques de Rennes, Université de Rennes 1 \& CNRS UMR 6226, Campus Beaulieu, 35042 Rennes, France.

E-mail: ie-rang.jeon@univ-rennes1.fr \& marc.fourmigue@univ-rennes1.fr

${ }^{b .}$ CNRS, ICMCB, UPR 9048, 33600 Pessac, France.

c. Univ. Bordeaux, ICMCB, UPR 9048, 33600 Pessac, France.

${ }^{d .}$ CNRS, CRPP, UPR 8641, 33600 Pessac, France.

e. Univ. Bordeaux, CRPP, UPR 8641, 33600 Pessac, France.

f. Institut de Physique de Rennes, Université de Rennes 1, UMR UR1-CNRS 6251, 35000 Rennes, France

+Electronic Supplementary Information (ESI) available: Experimental details, crystallographic data, crystal structure of 1 , additional optical and magnetic data, and crystallographic information files (CIF). CCDC 1550127-1550128 and 1568816. See DOI: $10.1039 / \times 0 \times x 00000 x$

alternative strategy. ${ }^{7}$ Despite these advances, the design of $\mathrm{Fe}^{\text {III }}$ spin crossover systems exhibiting the photoswitching effect still represents a formidable challenge to understand key parameters governing the lifetime of the photo-induced metastable phase of $\mathrm{Fe}^{\text {III }}$ compounds. Toward this end, we envision to harness halogen bonding interactions, ${ }^{11}$ that feature high directionality and strength, to rationally construct a supramolecular framework where $\mathrm{Fe}{ }^{\text {III }}$ molecules could be embedded. Such a network will serve not only to introduce the intermolecular elastic interactions but also to tune the spatial organization and the confinement of the guest molecules, both of which are potential important factors to activate or deactivate the LIESST effect.

We recently reported the implementation of anionic halogenbonded supramolecular networks to drastically change the spinstate of molecular guest complexes. ${ }^{12}$ The modulation of electronic and magnetic properties of the guest molecules stemmed from a significant modification of their crystal packing depending on the presence and the nature of the halogen bonding. Herein, we report the role of reaction solvent medium to control the inclusion of the molecular Fe"I complex into the halogen-bonded supramolecular network and to activate the "breathing" of the host network. As a consequence, the guest molecules undergo spin crossover, lightinduced spin state trapping, and photoswitching, providing an extremely rare example of a Fe"l' complexes whose spin state can be reversibly controlled both by light and temperature. It is important noting that the role of solvent is here a chemical tool to drastically modify the final supramolecular assembly, ${ }^{13}$ which differentiates this study from previous investigations of the solvation effect on spin crossover molecules. ${ }^{14}$

The halogen-bonded network encapsulating an Fe" complex was synthesized following previously reported procedures but with modification of the reaction solvent. ${ }^{11}$ The reaction of $\left[\mathrm{Fe}(q \mathrm{qsal})_{2}\right] \mathrm{Cl}$ (Hqsal $=\mathrm{N}$-(8-quinolyl)salicylaldimine) with a mixture of 17 eq. of sym-triiodotrifluorobenzene $\left(\mathrm{C}_{6} \mathrm{~F}_{3} \mathrm{I}_{3}\right)$ and 1.0 eq. of $\mathrm{KI}$ in $\mathrm{MeOH}$ yielded dark plate-like crystals of $\left[\mathrm{Fe}(\mathrm{qsal})_{2}\right]\left[\left(\mathrm{C}_{6} \mathrm{~F}_{3} \mathrm{I}_{3}\right) \mathrm{l}\right](\mathbf{1})$. The similar reaction in $\mathrm{MeCN}$ afforded dark needle-shaped crystals of a solvated compound $\left[\mathrm{Fe}(\mathrm{qsal})_{2}\right]\left[\left(\mathrm{C}_{6} \mathrm{~F}_{3} \mathrm{I}_{3}\right) \mathrm{l}\right] \cdot \mathrm{MeCN}$ (2), as previously reported. ${ }^{11}$ Single-crystal $\mathrm{X}$-ray analysis reveals that the structure of compound 1 consists of 2D honeycomb-like halogen-bonded framework $\left[\left(\mathrm{C}_{6} \mathrm{~F}_{3} I_{3}\right)\right]^{-}$, as observed in $\mathbf{2}$. This network results from the tritopic character of the halogen bond donor, $\mathrm{C}_{6} \mathrm{~F}_{3} \mathrm{I}_{3}$, and the three-fold coordination of the iodide anion as a halogen bond acceptor (Figures 1). The $|\cdots|^{-}$bond distances in 1 at $298 \mathrm{~K}$ are $3.532(8), 3.619(6)$, and 3.731(7) $\AA$, that are 15,13 , and $11 \%$ shorter than the sum of the van der Waals and ionic radii, respectively. These values indicate the employed halogen bonding interaction is more symmetric than those found in 2 that features 16,15 , and $3 \%$ reduction. The $2 \mathrm{D}$ network of $\mathbf{1}$ is distorted and undulated, similar to that of 2, with a central $\mathrm{I}^{-}$ion at ca. $0.9 \AA$ off from the plane formed by three iodine atoms (Figure S1). 


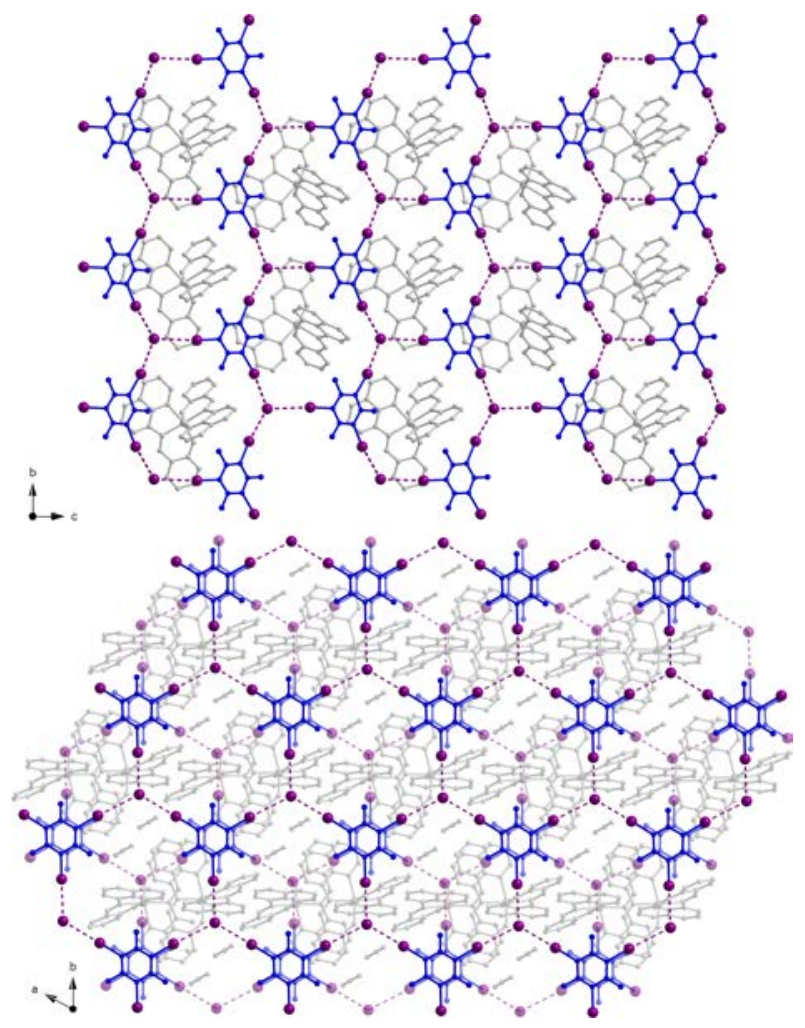

Figure 1. X-ray crystal structure of $\mathbf{1}$ and $\mathbf{2}$, as viewed along the crystallographic $a$ and $\mathrm{c}$ axes, respectively. The $\left[\mathrm{Fe}(\mathrm{qsal})_{2}\right]^{+}$cationic complexes and the $\left[\left(\mathrm{C}_{6} \mathrm{~F}_{3} \mathrm{I}_{3}\right) \mathrm{X}\right]^{-}$anionic halogen-bonded networks are shown in grey and blue, respectively, for clarity. Halogen bonding interactions are highlighted as the purple dashed lines with I atoms in purple spheres.

While the topologies of the individual halogen-bonded layer in $\mathbf{1}$ and $\mathbf{2}$ are very similar, overall structures feature major differences. The honeycomb-like layers in 1 at $250 \mathrm{~K}$ are stacked in a perfectly eclipsed arrangement along the crystallographic $a$ axis, in contrast to the layers in $\mathbf{2}$ revealing a staggered arrangement. This eclipsed stacking pattern in $\mathbf{1}$ gives rise to $1 \mathrm{D}$ channels with an average diameter of ca. $11.4 \AA$, defined by cross-pore l...F distances. In these channels, the molecular $\mathrm{Fe}^{\mathrm{III}}$ complex is placed between layers and features $\pi \cdots \pi$ and hydrogen bond interactions with the adjacent ones along the crystallographic $a$ axis, inducing an 1D assembly (Figure S2). The individual chain is then well isolated one another inside the 1D pores formed by the halogen-bonded framework. The average $\mathrm{Fe}-\mathrm{N}$ and $\mathrm{Fe}-\mathrm{O}$ distances in the molecular $\left[\mathrm{Fe}(\mathrm{qsal})_{2}\right]^{+}$unit are $2.140(8)$ and $1.910(7) \AA$, respectively, unambiguously indicating a high-spin $\mathrm{Fe}^{\text {III }}$ configuration at $298 \mathrm{~K}^{11}$

The observed molecular arrangement is remarkably different with that in 2, which consisted of dimerized Fe ${ }^{\text {III }}$ complexes and MeCN molecules between the pairwise halogen-bonded layers (Figures 1 and S1). Furthermore, structure of $\mathbf{2}$ featured extensive intermolecular interactions between the bulky dimerized $[\mathrm{Fe}]_{2}$ units and the network, which we attributed to the absence of spin crossover by trapping a high-spin state in the $2-300 \mathrm{~K}$ range. ${ }^{11}$ Taken together, the structural analysis indicates that the use of different reaction solvent media drastically altered the self-assembly fashion of $\mathrm{Fe}^{\text {III }}$ molecules during the formation of halogen-bonded supramolecular network and the guest inclusion process. In particular, the eclipsed halogen-bonded honeycomb layer in $\mathbf{1}$ (Figure 1 ) separates the densely packed $[\mathrm{Fe}]_{2}$ units, and therefore

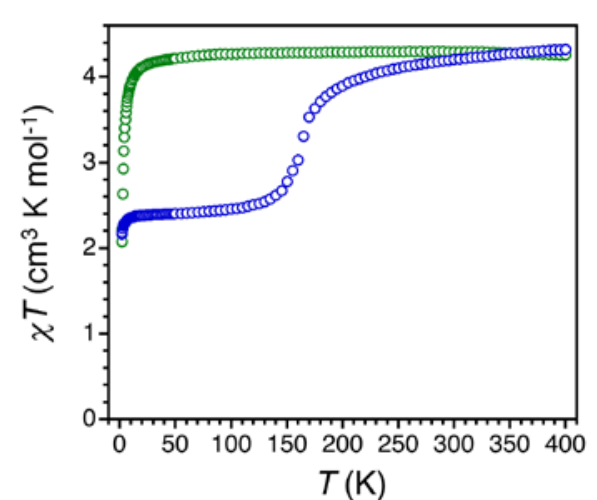

Figure 2. Variable-temperature dc magnetic susceptibility $(\chi=M / H$ per mole of compound) data for 1 (blue sphere) and $\mathbf{2}$ (green sphere), shown as a plot of $\chi T$ vs. $T$, collected under an applied field of $1 \mathrm{~T}$ from 400 to $100 \mathrm{~K}$ and $0.1 \mathrm{~T}$ below $100 \mathrm{~K}$ at a temperature sweep rate of $0.7 \mathrm{~K} \mathrm{~min}^{-1}$.

releases the structural rigidity, relative to that in $\mathbf{2}$, which may modulate the magnetic property.

To probe the temperature dependence of the structural changes in 1, the thermal evolution of the unit-cell parameters was investigated (Figure S3). Upon decreasing temperature, in addition to the linear thermal contraction, a noticeable abnormal jump was observed for $a, c$, and $B$ parameters between 150 and $180 \mathrm{~K}$, implying the presence of a first-order structural transition, in agreement with the discontinuous change of $\chi T$. A full data collection of 1 at $100 \mathrm{~K}$ indeed reveals a unit-cell doubling along the crystallographic $a$ and $b$ directions (Table S1), displaying the characteristic superstructure Bragg peaks at $Q=1 / 2 a^{*}+1 / 2 b^{*}$ (Figures S4 and S5). Consequently, the structure at $100 \mathrm{~K}$ features two distinct $\mathrm{Fe}^{\mathrm{III}}$ centers with the mean $\mathrm{Fe}-\mathrm{N} / \mathrm{Fe}-\mathrm{O}$ distances of

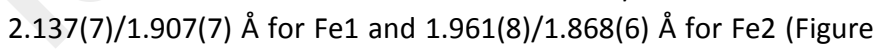
S6). The observed distances indicate a high-spin and a low-spin configurations for $\mathrm{Fe} 1$ and $\mathrm{Fe} 2$, respectively, which are alternating along the $a$ and $b$ directions (Figure S7). This is another manifestation of the formation of spin-state concentration waves (SSCW). ${ }^{15}$ Accordingly, there are two independent halogen bonding environments, as shown by the $|\cdots|^{-}$bond distances of 3.441(1), 3.514(1), and 3.599(2) $\AA$ for the site 1 and 3.493(1), 3.474(1) and $3.658(2) \AA$ for the site 2 (Figure S7). As a result, the 2D honeycomblike network is not anymore perfectly eclipsed along the $a$ direction (Figure S8). This proves that the flexibility of the halogen-bonded supramolecular network plays a key role to accommodate the structural changes associated with the spin crossover of Fe2.

In order to investigate the magnetic behaviour of $\mathbf{1}$, variabletemperature magnetic susceptibility data were collected on solid samples. The resulting plot of $\chi T$ vs. $T$ is shown in Figure 2 and compared with that of $\mathbf{2}$, which remains in a high-spin state in the whole temperature range. At $400 \mathrm{~K}$, the $\chi T$ value for 1 is 4.32 $\mathrm{cm}^{3} \mathrm{~K} / \mathrm{mol}$, which corresponds to the expected one for a high-spin $S$ $=5 / 2 \mathrm{Fe}$ "II' centre with $g=1.99$. As temperature is decreased, $\chi T$ product for 1 undergoes a gradual decrease and then an abrupt drop below $200 \mathrm{~K}$, to reach a value of $2.38 \mathrm{~cm}^{3} \mathrm{~K} / \mathrm{mol}$ at $20 \mathrm{~K}$. This thermal dependence clearly correlates with the partial spin state conversion observed by $\mathrm{x}$-ray diffraction, related to the formation of SSCW (Figure S9). The observed value at low temperature indicates ca. $50 \%$ of Fe centres are still in a high-spin state, which agrees well with the structural analysis at $100 \mathrm{~K}$. It is worth noting 


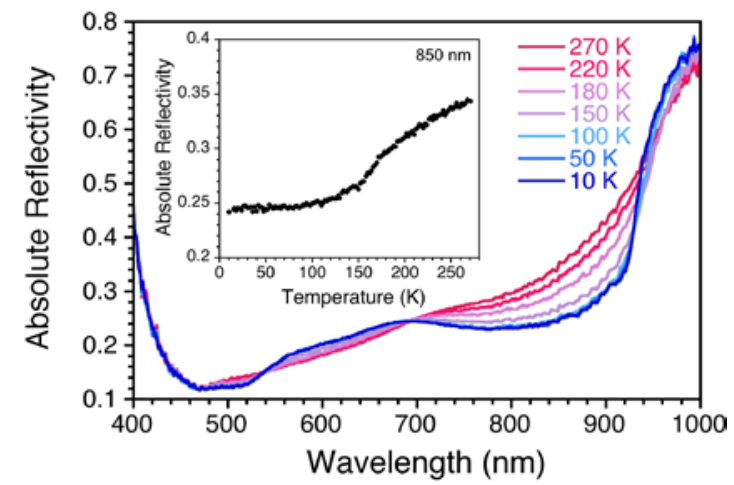

Figure 3. Surface optical reflectivity spectra of 1 at selected temperatures upon cooling from 270 to $10 \mathrm{~K}$ at $4 \mathrm{~K} / \mathrm{min}$. The experiment was performed in the dark except during the spectrum acquisition (spectroscopic white light during $1 \mathrm{~s}, P=0.8 \mathrm{~mW} / \mathrm{cm}^{2}$ ). Inset: Temperature-dependence of the optical reflectivity at $850 \mathrm{~nm}$ of 1 between 270 and $10 \mathrm{~K}$ on cooling in the dark (black dots).

that the susceptibility measured between 1.8 and $400 \mathrm{~K}$ is completely reversible, without a thermal hysteresis, indicating that $\mathbf{1}$ and $\mathbf{2}$ are robust materials and do not degrade up to $400 \mathrm{~K}$ (Figure S10).

To further assess the spin crossover process, variabletemperature optical reflectivity was measured on a solid sample of 1 (Figure 3). At $270 \mathrm{~K}$, the spectrum reveals a broad absorption band in the range $400-900 \mathrm{~nm}$. Upon cooling, the spectrum is smoothly modified down to $100 \mathrm{~K}$, and no further significant change was observed between 100 and $10 \mathrm{~K}$. The final spectrum at $10 \mathrm{~K}$ exhibits two distinct bands at 500 and $850 \mathrm{~nm}$. To better visualize the thermal evolution of the optical properties, the absolute reflectivity at $850 \mathrm{~nm}$ is plotted as a function of temperature (Figure 3 inset), showing a $S$-shaped gradual decrease. This temperature dependence of the absolute reflectivity corresponds to the thermal evolution of $\chi T$ product, indicating that the observed surface thermochromism mainly originates from the bulk spin crossover properties.

In order to investigate the potential photosensitivity of 1, the solid sample was cooled down in the dark at $10 \mathrm{~K}$ and then irradiated with selected wavelengths using LED sources for 10 minutes $\left(P=2 \mathrm{~mW} / \mathrm{cm}^{2}\right)$. The optical spectra of before and after irradiation were compared in Figure S4. The difference in the absolute reflectivity at $850 \mathrm{~nm}$ reveals an efficient photoconversion with LED sources of 850 and $940 \mathrm{~nm}$. This spectral domain corresponds to the absorption band developed at $10 \mathrm{~K}$, which indicates that this band is likely a ligand-to-metal charge transfer absorption of the low-spin Fe' complex. Given the narrow selectivity in wavelength for the photoexcitation, the photoreversibility was also monitored by a successive irradiation at selected wavelength $\left(P=2 \mathrm{~mW} / \mathrm{cm}^{2}\right)$, once the sample is fully excited with a $940 \mathrm{~nm}$-irradiation. The photoreverse effect is efficient in a broad range of spectral domain, with an optimum wavelength around $600 \mathrm{~nm}$ (Figure S11). Lastly, the photoswitching was investigated using the selected 940 and $625 \mathrm{~nm}$ irradiations. As shown in Figure S12, the absolute surface reflectivity at $850 \mathrm{~nm}$ shows perfectly reversible cycles, demonstrating a good photoreversibility in $\mathbf{1}$.

To analyze the effect of the photosensitivity on bulk magnetic properties, photomagnetic measurements were performed (Figure 4). The solid sample of $\mathbf{1}$ was cooled to $10 \mathrm{~K}$ in the absence of light
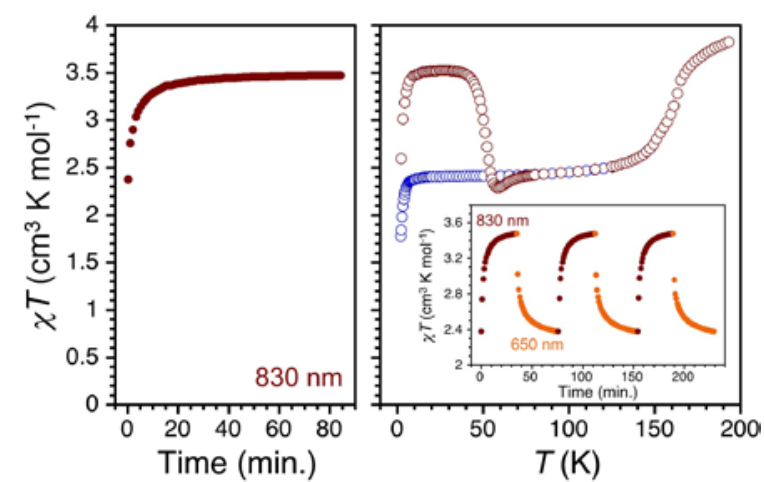

Figure 4. Dc magnetic susceptibility data for 1 collected under an applied field of $1 \mathrm{~T}$. Left: A plot of $\chi T$ vs time under an $830 \mathrm{~nm}$-irradiation $\left(P=3.7 \mathrm{~mW} / \mathrm{cm}^{2}\right)$ at $10 \mathrm{~K}$. Right: Plots of $\chi T$ vs temperature at $0.4 \mathrm{~K} / \mathrm{min}$ before (blue) and after (brown) an $830 \mathrm{~nm}$ irradiation $\left(P=3.7 \mathrm{~mW} / \mathrm{cm}^{2}\right)$ at $10 \mathrm{~K}$. Inset: A plot of $\chi T$ vs time under a succession of $830 \mathrm{~nm}$-irradiation (for $40 \mathrm{~min} ., P=3.7 \mathrm{~mW} / \mathrm{cm}^{2}$ ) and $650 \mathrm{~nm}$-irradiation (for $40 \mathrm{~min}$., $P=12.6 \mathrm{~mW} / \mathrm{cm}^{2}$ ) at $10 \mathrm{~K}$.

before being exposed to an $830 \mathrm{~nm}$-light $\left(P=3.7 \mathrm{~mW} / \mathrm{cm}^{2}\right)$. As shown in the left part of Figure 4 , the $\chi T$ product quickly increases and saturates to $3.49 \mathrm{~cm}^{3} \mathrm{~K} / \mathrm{mol}$ in less than an hour, which indicates the efficient generation of the metastable high-spin state at the bulk level. The partial conversion estimated at ca. $59 \%$ is likely due to the intense colour and the shiny nature of the microcrystalline sample of $1 .{ }^{\ddagger}$ Upon increasing temperature, the metastable state is thermally trapped up to $40 \mathrm{~K}$. Around $50 \mathrm{~K}$, the photoinduced high-spin state relaxes to the thermodynamic lowspin state, confirming the presence of the LIESST effect. Note that the observed photoexcitation efficiency (at least 59\%) is far superior to that reported for any $\left[\mathrm{Fe}^{\mathrm{III}}(\mathrm{qsal})_{2}\right]^{+}$units showing a LIESST effect, which feature a weak photoconversion of less than $10 \%{ }^{5,6}$ Right after the relaxation around $53 \mathrm{~K}$, the $\chi T$ product shows a drop lower than the value for the non-irradiated sample at the same temperature. The $\chi T$ value then gradually increases to recover at $80 \mathrm{~K}$ the data before irradiation upon further heating. To further analyse this feature, we measured the magnetic susceptibility at a fixed temperature of $53 \mathrm{~K}$ after photoexcitation (Figure S13). Nevertheless, the $\chi T$ product remains at a quasiconstant value after an hour, indicating that a combined effect of the low thermal energy and the limited structural flexibility of the compound likely prevents to access to the fully low-spin state.

The efficient photoexcitation and the thermal trapping of the metastable phase enabled us to test the photoreverse effect on a bulk sample of 1 by photomagnetic measurements. At $10 \mathrm{~K}$, the crystalline sample was first exposed during 40 minutes to a $830 \mathrm{~nm}$ light $\left(P=3.7 \mathrm{~mW} / \mathrm{cm}^{2}\right)$, and then a $650 \mathrm{~nm}$-light $\left(P=12.6 \mathrm{~mW} / \mathrm{cm}^{2}\right)$ was used for another 40 minutes. During this sequence of irradiations, the magnetic susceptibility was measured and the resulting plot of $\chi T$ vs. time is shown in inset of Figure 4. Remarkably the data shows excellent reversibility and reproducibility during three successive cycles of irradiations, highlighting the efficient solid-state photoswitching of spin-state in 1. To our knowledge, this is the first example of a reversible photoconversion in compounds containing $\left[\mathrm{Fe}^{\text {III }}(\text { qsal })_{2}\right]^{+}$units.

To have an insight into the unprecedented reversible photoswitching effect in $\mathbf{1}$, we have compared the structural differences with the few literature examples containing the $\left[\mathrm{Fe}^{\text {IIII }}(\mathrm{qsal})_{2}\right]^{+}$unit and exhibiting a photomagnetic effect. ${ }^{5}$ For the 
mean $\mathrm{Fe}-\mathrm{N}$ and $\mathrm{Fe}-\mathrm{O}$ bond lengths between high-spin and low-spin states, the reported compounds show a contraction by $0.150-0.167$ and $0.003-0.018 \AA$, respectively. In contrast, the corresponding shortening in 1 amounts to 0.187 and $0.043 \AA$, and accordingly is much larger than that observed in the reported examples. As such, the more significant structural change in the photoexcited high-spin state is anticipated for $\mathbf{1}$, which may help to avoid the fast relaxation of the metastable phase. Such a structural distortion effect has been previously proposed in other $\mathrm{Fe}^{\text {III }}$ systems as well. ${ }^{4,7}$ Furthermore, the rare observation of the LIESST effect in known $\left[\mathrm{Fe}^{\text {III }}(\mathrm{qsal})_{2}\right]^{+}$complexes, in conjunction with its low efficiency, has been attributed to an overlap of the LIESST and the reverse LIESST bands. $^{5}$ In contrast, compound $\mathbf{1}$ shows a distinct difference between the spectral bands for the photoexcitation and the reverse photoconversion, which likely stems from a combined effect of the substantial structural distortion and the significant intermolecular interactions with the host supramolecular network. Taken together, the optimized structural confinement and complexity provided by halogen-bonded network play a key role to favourably access and trap the metastable phase, which enables the reversible photoswitching.

The foregoing results describe a drastic solvent-induced modification in the organization of a guest $\mathrm{Fe}^{\mathrm{III}}$ complex inside a halogen-bonded supramolecular network. In particular, the induced structural relief triggers the breathing of the host network to accommodate the spin crossover and the reversible photoswitching of the spin-state of the guest molecule. Work is underway to further control the inclusion process of guest functional molecules into the host framework, for example by increasing the pore size of the halogen-bonded networks using larger neutral tris-iodinated spacers. ${ }^{16}$

This research was supported by the French National Research Agency Grant ANR 16-ACHN-0007. I. -R. J., O. J., and M. F. thank the CDIFX in Rennes for the use of X-ray diffractometer. C. M., R. C., and M. R. thank the University of Bordeaux, the CNRS, and the Nouvelle Aquitaine Region.

\section{Notes and references}

¥ The conversion percentage is calculated using a following equation: $\left(\chi T_{400 K}-\chi T_{20 K}\right) /\left(\chi T_{20 K, h v}-\chi T_{20 K}\right) \times 100$.

1 K. Nasu, Photoinduced Phase Transitions; World Scientific Publishing, Singapore, 2004; S. Koshihara and M. KuwataGonokami, ed., J. Phys. Soc. Jpn., 2006, 75, 011001; R. Bertoni, M. Lorenc, A. Tissot, M.-L. Boillot and E. Collet, Coord. Chem. Rev., 2015, 282, 66.

2 S. Decurtins, P. Gütlich, C. P. Köhler, H. Spiering and A. Hauser, Chem. Phys. Lett., 1984, 105, 1; S. Decurtins, P. Gütlich, K. M. Hasselbach and A. Hauser, Inorg. Chem., 1985, 24, 2174; H. Spiering and A. Hauser, Top. Curr. Chem., 2004, 234, 155.

3 A. Bousseksou, G. Molnár, L. Salmon and W. Nicolazzi, Chem. Soc. Rev., 2011, 40, 3313; M. A. Halcrow, Spin-Crossover Materials: Properties and Applications, John Wiley \& Sons, 2013.

4 S. Hayami, Z. Gu, M. Shiro, Y. Einaga, A. Fujishima and O. Sato, J. Am. Chem. Soc., 2000, 122, 7126.

5 S. Hayami, K. Hiki, T. Kawahara, Y. Maeda, D. Urakami, K. Inoue, M. Ohama, S. Kawata and O. Sato, Chem. Eur. J., 2009, 15, 3497.
6 K. Takahashi, H. Cui, H. Kobayashi, Y. Einaga and O. Sato, Chem. Lett., 2005, 34, 1240.

7 M. Clemente-Léon, E. Coronado, M. López-Jordá, C. Desplanches, S. Asthana, H. Wang and J.-F. Létard, 2012, Chem. Sci., 2011, 2, 1121; M. Clemente-Léon, E. Coronado, M. López-Jordá, J. C. Warenborgh, C. Desplanches, H. Wang, J.-F. Létard, A. Hauer and A. Tissot, J. Am. Chem. Soc., 2013, $135,8655$.

8 K. D. Murnaghan, C. Carbonera, L. Toupet, M. Griffin, M. M. Dîrtu, C. Desplanches, Y. Garcia, E. Collet, J.-F. Létard and G. G. Morgan, Chem. Eur. J., 2014, 20, 5613; K. Takahashi, K. Kawamukai, M. Okai, T. Mochida, T. Sakurai, H. Ohta, T. Yamamoto, Y. Einaga, Y. Shiota and K. Yoshizawa, Chem. Eur. J., 2016, 22, 1253; E. W. T. Yemeli, G. R. Blake, A. P. Douvalis, T. Bakas, G. O. R. Alberda van Ekenstein and P. J. van Koningsbruggen, Chem. Eur. J., DOI 10.1002/chem. 201002100

9 R. Berthoni, M. Lorenc, A. Tissot, M.-L. Boillot and E. Collet, Coord. Chem. Rev., 2015, 282-283, 66.

10 D. J. Harding, P. Harding and W. Phonsri, Coord. Chem. Rev., 2016, 313, 38.

11 P. Metrangolo, H. Neukirch, T. Pilati and G. Resnati, Acc. Chem. Res., 2005, 38, 386; F. Mayer and P. Dubois, CrystEngComm, 2013, 15, 3508; G. Cavallo, P. Metrangolo, R. Milani, T. Pilati, A. Priimagi, G. Resnati and G. Terraneo, Chem. Rev., 2016, 116, 2478.

12 I.-R. Jeon, O. Jeannin, R. Clérac, $M$. Rouzières and $M$. Fourmigué, Chem. Commun., 2017, 53, 4989.

13 C. Li and M. Du, Chem. Commun., 2011, 47, 5958; J. Wang, K. Liu, L. Yan, A. Wang, S. Bai, and X. Yan, ACS Nano, 2016, 10, 2138.

14 W. Phonsri, P. Harding, L. Liu, S. G. Telfer, K. S. Murray, B. Moubaraki, T. M. Ross, G. N. L. Jameson, and D. J. Harding, Chem. Sci., 2017, 8, 3949.

15 H. Watanabe, K. Tanaka, N. Bréfuel, H. Cailleau, J.-F. Létard, S. Ravy, P. Fertey, M. Nishino, S. Miyashita, E. Collet, Phys. Rev. B, 93, 014419 .

16 J. Lieffrig, O. Jeannin and M. Fourmigué, J. Am. Chem. Soc., 2013, 135, 6200; M. Fourmigué, Acta Cryst., 2017, B73, 138.

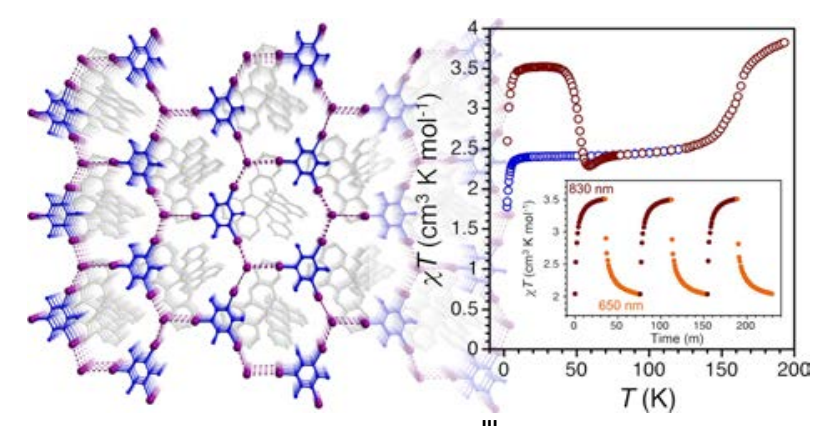

The organization of a molecular Fe" complex embedded in a halogen-bonded 2D network is chemically tuned to trigger temperature and light-induced spin-state switching. 